\title{
An internet is one of the most powerful tool for remote Medical Consultation for peers
}

\author{
Sanong Suksaweang* and Khongpakorn Sangmas \\ Institute of Medicine, Suranaree University of Technology, Thailand \\ *Corresponding author: Sanong Suksaweang, Institute of Medicine, Suranaree University of Technology, Thailand. \\ To Cite This Article: Sanong Suksaweang. An internet is one of the most powerful tool for remote Medical Consultation for peers. Am J Biomed \\ Sci \& Res. 2019 - 4(1). AJBSR.MS.ID.000743. DOI: 10.34297/AJBSR.2019.04.000743
}

Received: June 08, 2018 | Published: July 12, 2019

\begin{abstract}
In order to get help, sometimes people can be assisted via a modern social network service like Facebook. This friend of mine was timely helped just the right time before he did anything wrong into his own help condition. Via regular check Facebook posting, I found his post very striking in term of picture and the question. I, therefore, took action immediately as I should. Luckily, he complied to my advice and got the right intervention with his doctor. In my opinion, Facebook can be one of the interesting tools for our medical personals to think about when it comes to Health services.
\end{abstract}

\section{Main Text}

This is an interesting case actually happening with me before I wrote this article. A week before the end of June, a friend of mine posted the picture of his infecting-like finger (Figure 1) on his Facebook and I immediately give him an advice before he went to see his doctor [1]. This kind of reaction looks almost like erysipelas [2] an acute cutaneous and subcutaneous inflammation caused by hemolytic streptococcus [3] (Figure 1).

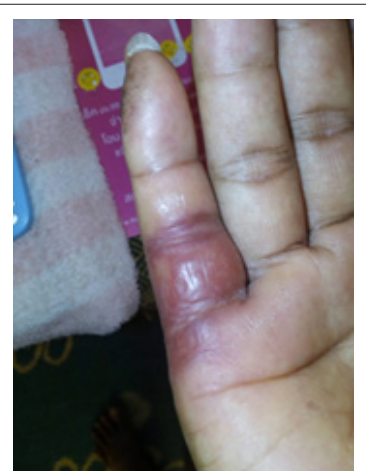

Figure 1: The first time the patient posted in his own Facebook. His right pinky finger is showing a red and somewhat swelling lesion locally at the base of finger.

The best advice for this kind of lesion is not to make any hole into it because you can introduce other microorganism into the lesion unintentionally. Therefore, I gave the advice and asked him to see his doctor right afterward. The pro and con of using Facebook is incredible, for this, he receives my advice just before his attempt for perforating the lesion with uncleaned needle. I also added, even he used the clean needle that will also can create the open wound, which susceptible to any infection. Luckily, he complied to my advice and he went to see the doctor for further thoroughly evaluation. As expected, his doctor asked him to leave the lesion as it is and give some medication for relevant symptoms. He came back to his house and took care of himself as good as possible by not to irritate the lesion with regular daily life. Five days later, he posted again with a much more redness picture (Figure 2).

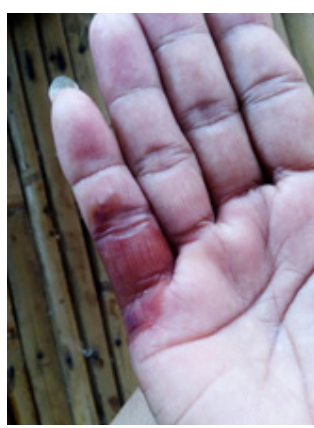

Figure 2: The second time the patient posted in his own Facebook His right pinky finger is showing a much redder but no sign of swelling lesion.

He mentioned something that is informative, telling people that not to worry because his finger is actually getting better. He had this kind of episode long time ago and he forgot. To me, this is one of the most memorable events for using Facebook to observe any kind of misunderstanding and do self-care intervention of our people. Facebook is so widely used around the world and I 
am one of those who became a member since it was launched in 2004 before I graduated from University of Southern California on March 2005. More than 2000 million people are using the Facebook now and increasing every day. This social network service is widely applicable to our walk of life including medical personal.

For this patient, not only I helped him deciding what to do but I also can chat with him personally for deeper information regarding the infection of haemolytic streptococcus [3]. His post also received many other useful advices from other friends as well. Particularly, those who doesn't have any medical knowledge are really good for mental support in which very powerful. Therefore, it is great to use the Facebook not only to our personal liking, but also to help other look after their health problems timely. To save someone's life even with a small step, it is worth of practicing.

\section{References}

1. Facebook.

2. Celestin R, Brown J, Kihiczak G, Schwartz RA (2007) Erysipelas: a common potentially dangerous infection. Acta Dermatovenerol Alp Pannonica Adriat 16(3): 123-127.

3. Kenneth Todar Streptococcus pyogenes and Streptococcal Disease. 